\title{
Wine and the Consumer Price-perceived Quality Heuristics
}

\author{
Freddy S. Lee \\ California State University at Los Angeles \\ 5151 State University Drive, Los Angeles CA 90032, USA \\ Tel: 1-323-343-2967 E-mail: flee@exchange.calstatela.edu
}

Received: April 8, 2012 Accepted: May 16, 2012 Published: June 1, 2012

doi:10.5539/ijms.v4n3p31 URL: http://dx.doi.org/10.5539/ijms.v4n3p31

\begin{abstract}
Does price have anything to do with Wine? The consumer price-perceived quality has always been used by consumers when they gauge the quality of a product or service. In this article, we develop three propositions which show how the consumer uses the price-perceived quality in the wine industry. For all types of wines, there will be attributes like ratings, brand name and word of mouth that will affect the purchase. The goal in this paper is to offer propositions that can motivate empirical research pertaining to the factors that influence how consumers use the price-perceived quality heuristic to determine which wine is worth the money that they are paying for. The findings will point to several ways that wine sellers can realign programs and reallocate resources to raise profitability levels and reduce costs. Primary among them are the development and articulation of whether to upgrade to meet the rating criteria, whether to invest in the brand name or to address public perception through viral marketing.
\end{abstract}

Keywords: Price-perceived quality heuristic, Wine, Rating, Brand perception, Viral marketing, Proposition

\section{Introduction}

Wine Spectator stated that "price has nothing to do with wine" while in Hibbs, Jensen, Sraiheen (2011), an analysis reveals a statistically significant positive correlation between price and quality. For many ordinary consumers, buying wine is largely based on recommendations or with reference to price. Consider the following headline from the Wall Street Journal (December 4, 1996 p A2), "A jewelry-store owner instructs the shop clerk to cut prices on turquoise, to clear the merchandise. The clerk mistakenly raises prices instead. Quickly, all the merchandise sells, because unsophisticated buyers associate high prices with high quality.” The price-perceived quality heuristic is one of the most important heuristics in consumer behavior (Chao and Schor, 1988; Erickson and Johansson, 1985; Lichtenstein and Burton, 1989; Monroe and Krishnan, 1985; Stafford and Enis, 1969; Zeithaml, 1988). Previous studies found that the use of this heuristic is a common behavioral feature among consumers (Stafford and Enis, 1969; Monroe and Krishnan, 1985; Erickson and Johansson, 1985; Zeithaml, 1988), and that even though the heuristic exists in many product categories, it is particularly strong for status-oriented products, durable goods, and products that are difficult to evaluate (Chao and Schor, 1988; Gerstner, 1985; Lichtenstein and Burton, 1989; Owen, Wright and Griffin, 2000).

Wine is definitely one of the aspects of consumer purchase where gauging the quality is subject to a multitude of factors and parameters like age, appellation, the process, the packaging etc. The relationships between wine quality and price per bottle or case is hence of great interest. This is especially so given the growing consumption for wine in developed countries, the higher expectations of the growing middle class as well as the importance of wine in fine dining in today's economies of emerging markets. The wine market in China reached $125 \mathrm{~m}$ cases in 2010, making it the fastest growing major still light wine market with growth of $34.4 \%$ on 2009 . (Wehring, 2011).

For many seasoned wine lovers, gauging quality prior to purchase and tasting is something done through experience and awareness of source. However for majority of the layman customers in the market, gauging the quality is often via price on the wine list. Thus this lead to restaurant owners and managers needing to know about the consumer's-perceived quality heuristic to be able to better fairly price the rack rates and position the quality perception in the consumers' mind.

For the consumer dining in a restaurant or who had limited experience tasting different types of wine, looking at 
a wine list or menu is how wine is ordered. The customer generally believe that the higher the price on the menu, the higher the wine quality. The customer is assuming the specialty of the grapes used to produce the wine or the process or the appellation or age or some other attributes that will command the price as indicated. Our goal in this paper is to offer propositions that can motivate empirical research pertaining to the factors that influence how consumers use the price-perceived quality heuristic to determine whether the wine product purchased is worth the money that they are paying for. We identify three potential areas that become salient in these circumstances and in which wine sellers can better understand their threshold market behavior: Ratings, Brand Perception and Word of Mouth.

\section{The Consumer Price-perceived Quality}

There are two opposite effects to distinguished based on previous research on the role of price. First, price in the budget constraint is associated with the expenditure items. The theory of resource allocation explicitly states that consumers will treat it as a sacrifice of monetary resource as spending in one product necessarily decreases the possible purchase of another. Second, a higher price is usually taken as an indication of higher quality, even though the significance of such perceived correlation may vary across product categories (Lichtenstein and Burton 1989). This positive role exists as price helps to form a belief or perception about quality, which then influences the purchase intention (Erickson and Johansson, 1985; Monroe and Krishnan, 1985). The conceptual framework of Erickson and Johansson (1985) compactly joins these two distinctive effects. Figure 1 illustrates this framework, which helps construct a consumer utility function that incorporates the price-perceived quality heuristic into classic quantitative setups (Mussa and Rosen, 1978; Moorthy 1984, 1988).

\section{Insert Figure 1 here}

Since perceived quality $\left(s_{h}\right)$ is formed based on true quality $(s)$ and the price level $(p)$, we specify that the overall value of $s_{h}$ is derived from two components $-s$ and $p$, and that $s_{h}$ is an increasing function of both. Parameter $\delta_{s}$ $\left(0<\delta_{s} \leq 1\right)$ is used to represent the fraction of true quality information that is known to consumers, and parameter $\delta_{p}$ represents the weight that consumers place on price $p$ when assessing perceived quality $s_{h}$. In other words, higher product quality and a higher price will result in higher perceived quality for the average consumer. Besides the support from the behavioral literature discussed earlier, these parameters are also consistent with the studies that indicate product quality information cannot be fully conveyed or evaluated by consumers prior to purchase (Chang and Wildt 1996; Nelson 1970; Shapiro 1982). To ensure that the effect of price on quality is not greater than its effect as a budgetary constraint, we confine our analysis to $0 \leq \delta_{p} \leq 1$.

Another issue in the formulation is the degree of dependence between the use of price-perceived quality heuristic and the amount of true quality information available. Existing research is inconclusive on this. On one hand, one may argue that the more information available to consumers, the less they will rely on price to judge quality. For example, Zeithaml (1988) shows that the availability of intrinsic cues to quality affects the price-perceived quality relationship. On the other hand, other studies suggest that the use of price-perceived quality heuristic is an intrinsic behavioral characteristic of consumers, and they still adopt it even if their knowledge of the products is increased by communication or personal usage (e.g., Lichtenstein and Burton 1989). Because of the different perspectives, we allow the degree of dependence to vary and in this paper, $\delta_{p}$ and $\theta$ (see equation 1) will be the parameters that captures the three potential areas that may affect the consumer price perceived-quality heuristic usage: Ratings, Brand Perception and Word of Mouth.

Lee, Liu and Weinberg (2005) capture the weighted combination of true quality $(s)$ and price $(p)$ and the varying degree of dependence between the use of the price-perceived quality heuristic and the availability of true quality information as follows,

$$
s_{h}=\delta_{p}\left(1-\theta \delta_{s}\right) p+\delta_{s} s
$$

Parameter $\theta$ captures the strength of this dependence. $\theta=0$ implies no dependence, and $\theta=1$ implies complete dependence. If $\delta_{p}=0$, price plays no role in quality perception. Note that, first, we focus on the across-category variations in the use of the price-perceived quality heuristic. It is possible that there can be both category level and individual level variation in the use of the price quality heuristic (Lichtenstein and Burton 1989). An analysis of empirical data was conducted to examine the comparative strength of the price-perceived quality heuristic across categories versus across consumers. The results show that while the across-category variance significantly explains the overall variance in the level of price-perceived quality heuristic reported by subjects, the across-subject variance does not. As a result, focusing on the across-category effect in our theoretical framework (i.e., $\delta_{p}$ varies between 0 and 1 depending upon categories) appears to be reasonable. Our model and its results are still be applicable across segments where consumer segments differing in the use of price-perceived quality heuristic are identified. Equation (1) captures the mean response that a consumer would 
hold for any given set of parameter values. While the model does not have an explicit term for possible uncertainties in quality perception (i.e., a consumer may estimate the true quality with either positive or negative errors), it is consistent with the positioning literature where utility functions do not include error terms (Neven and Thisse 1990; Moorthy 1988), and still allows for consumers to either overestimate or underestimate product quality. That is, depending upon parameter values, $s_{h}$ may be greater or less than (or equal) $s$. We leave the issue of a full uncertainty model for future research.

\section{Illustration}

\subsection{Wine Ratings}

The rating of wine has been found to be reliable and consistent over time according to researchers at the Center for Hospitality Research at Cornell University (2008) Thompson et. al. Scores from Wine Spectator, The Wine Advocate and International Wine Cellar relative to forty-four Bordeaux wine producers were investigated. There was a high correlation of raters and this means that there are consistent intrinsic characteristics that raters are capturing in their scores. It is thus accepted that quality cues have evolved over time for the evaluation of wine and these lead to reliable ratings. A linear model to determine the consistency was used by Shewbridge (1998).

For the International Wine Cellar, wines are scored relative to their peer group based on their expected quality during their period of peak drinkability. A score of 75 would be average while a score of 95 would be extraordinary. For the Wine Advocate, a score of 98 would be the pinnacle of quality while a score of 80 would be acceptable. For Wine Spectator, a score of 95 would be a classic wine while a 75 is a minor flawed wine.

As the rating information pertains to the appellation, age, taste and production, consumers will have a proxy to the perceived quality of the wine. As the scores are absolute relative to ratings, there is less reliance on price to perceive the quality. With more available quality information, consumers will naturally depend on the information. Thus with this in perspective, we propose proposition 1:

$P_{1}$ : Consumers rely less on the price-perceived quality for higher rated wine. Also the availability of information at a higher wine means that the dependence on quality information is higher.

$$
\delta_{p(\text { LowRated })}>\delta_{p(\text { HighRated })} \text { and } \theta_{\text {LowRated }}<\theta_{\text {HighRated }}
$$

\subsection{Brand Perception}

Brand perceptions strongly influence buying behavior (Romaniuk and Sharp (2002)), and is key to a successful marketing communication strategy. Firms look to image studies to explain current marketplace performance, eg. numbers of units sold and price gained. In the case of wine, ratings of wines are often used to benchmark the brand perception of the wine. Romaniuk and Sharp (2002) indicated that generally the more positively the brand is perceived by the marketplace (potential casual wine drinkers and the wine enthusiasts), the more the consumers (or potential guests) will buy. Brand perceptions can come from a variety of sources including consumer experiences, marketing, communications or word of mouth. Basically, any information that is encountered with the brand name when sufficiently processed will be linked to the brand name in memory and thus become part of that brand's image. Whether the consumer has a positive or negative perception of a certain brand will certainly affect the way consumers use the consumer price-perceived quality heuristic to infer quality and that will also determine whether they rely on quality information as well to perceive quality.

Wine production is available in many continents and because of the thousands of wineries to choose from, there are likewise thousands of brands to choose from as many wineries also have dozens of products under one label with many vintages under each product brand. In brief, this presents an infinite list of brands for the casual wine drinker. Subsequently, the consumer is forced to make choices among many brands and appellations that vary in quality and quantity every year. When presented with multiple unknown brands, the consumer is likely to rely more on the price-perceived quality. Subsequently if the brands are known at least to the potential wine buyer, the dependence on the quality information becomes salient. Hence we propose Proposition 2:

$P_{2}$ : Consumers rely less on the price-perceived quality for more known wine brands than less known wine brands. Also the availability of quality information through the brand means that the dependence on quality information is higher.

\subsection{Word of Mouth}

$$
\delta_{p(\text { more_knownbrand })}<\delta_{p(\text { less_knownbrand })} \text { and } \theta_{\text {more_knownbrand }}>\theta_{\text {less_knownbrand }_{-}}
$$

Word of mouth advertising was based largely of personal referrals before the arrival of the Internet. (Johnson 2007). However, multiple social media outlets on the internet now provides avenues for consumers to voice their opinions and feedback about product and services that they had purchased. One such outlet would be Yelp.com, 
a user-generated review site/social network that has changed the way local businesses do their marketing. According to Nielsen/NetRatings, Yelp has 1.8 million users a month.

Effective word of mouth is customer-driven, not company-driven. (Macleod 2009). Word of mouth is typically from consumers claiming independence from media influence and content is largely decided by the contributor. The word of mouth feedback or comment when aggregated provides a valuable source of demographic and psychographic data along with consumer perception and experience of the purchase. Thus monitoring word of mouth, whether negative or positive, gives business owners valuable marketing feedback and at the same time it also indirectly provides cross sectional information about the purchase per feedback.

The perception of quality through word of mouth about a wine whether positive or negative from consumers is that it implies quality of the wine. As a consequence, this will mean that the higher perceived quality from positive word of mouth about a wine would reduce the reliance on the price-perceived quality. In the case of more negative word of mouth about the wine, the objective information about the perceived quality would be heavily relied on.

Thus we propose proposition 3:

$P_{3}$ : Consumers rely less on the price-perceived quality for positive word of mouth about wine. Also the implied quality information through negative word of mouth means that the dependence on quality information is higher.

\section{Conclusion}

$$
\delta_{p(-v e W O M)}>\delta_{p(+v e W O M)} \text { and } \vartheta_{-v e W O M}>\theta_{+v e W O M}
$$

Wine consumption is on the rise worldwide. A few, major global players make up the entire wine industry. These few players own hundreds of brands. There are also intermediate sized companies with national and some international distribution, and hundreds of smaller, independent wineries. The Wine Institute reports 2,843 bonded wineries in California (2008) alone. Most of these would be considered small businesses by U. S. government standards. (Hibbs, Jensen, Sraiheen (2011)).

In developing this article, we hope to provide a framework for discussion, action and further empirical validation on the issue of wine perceived quality with respect to three factors; Ratings, Brand Perception and Word of Mouth. More consumers in developed and emerging markets are now being exposed to wine when they dine and a lack of knowledge about wine quality often would mean a reliance on the price to gauge quality.

Through the motivation in this article, we hope that future researchers will be able to design studies that can empirically validate these propositions. The findings will point to several ways that wineries and wine sellers can realign programs and reallocate resources to raise profitability levels and reduce costs. Primary among them is the connection between ratings and actual wine quality, whether to invest in the brand name or how to monitor word of mouth and viral marketing to realign their marketing mix.

\section{Acknowledgement}

I would like to thank Professor Yong Liu for all the advice and encouragement he had rendered me over the past decade in developing the conceptual framework of my research.

\section{References}

Chao, A., \& Schor, J. (1998). Empirical tests of status consumption: Evidence from women's cosmetics. Journal of Economic Psychology, 19(1), 107-131. http://dx.doi.org/10.1016/S0167-4870(97)00038-X

Erickson, G., \& Johansson, J. (1985). The Role of Price in Multi-Attribute Product Evaluations. Journal of Consumer Research, 12, 195-199. http://dx.doi.org/10.1086/208508

Gerstner, E. (1985). Do Higher Prices Signal Higher Quality? Journal of Marketing Research, 22(May), 209-215. http://dx.doi.org/10.2307/3151366

Hibbs, Jensen, Sraiheen. (2011). The relationship betwen wine rating, price, quantity produced and appelation among 2006 California Chardonnays with small producer recommendations. International Journal of Business and Social Science, 2(12), 14-21.

Johnson, J. (2007). Monitoring Word of Mouth, a powerful medium. The Colorado Springs Business Journal, 1.

Jones, P. (1988). Quality, capacity and productivity in service industries. International Journal of Hospitality Management, 7(2), 104-112. http://dx.doi.org/10.1016/0278-4319(88)90031-X

Laube, James. (2008). What Now for Wine Lovers. Wine Spectator, 4, 37. 
Lee, Liu \& Weinberg. (2005). Modeling the Effects of Consumer Price-Perceived Quality Heuristic on Marketing Strategies. Working Paper.

Lewis, B. (1989). Quality in the Service Sector: A Review. International Journal of Bank Marketing, 7(5), 4 - 12. http://dx.doi.org/10.1108/02652328910134590

Lichtenstein, D., \& Burton, S. (1989). The Relationship Between Perceived and Objective Price-Quality. Journal of Marketing Research, 26(Novermber), 429-43.

MacLeod, L. (2009). Boost Business by Marketing Word of Mouth. Daily Journal of Commerce, Portland.

Monroe, K., \& Krishnan, R. (1985). The Effect of Price on Subjective Product Evaluations. Perceived Quality: How Consumers View Stores and Merchandise. J. Jacoby and J. Olson, Lexington, MA, D.C. Health, 209-232.

Moorthy, K. S. (1984). Market Segmentation, Self-Selection and Product Line Design. Marketing Science, 3(4), 288-307. http://dx.doi.org/10.1287/mksc.3.4.288

Mussa, M., \& Rosen, S. (1978). Monopoly and Product Quality. Journal of Economic Theory, 18, 301-317. http://dx.doi.org/10.1016/0022-0531(78)90085-6

Neven, D., \& Thisse, J-F. (1990). On Quality and Variety Competition. Economic Decision Making: Games, Econometrics and Optimization. Amsterdam: North-Holland, 175-199.

Owen, K., Wright, V., \& Griffith, G. (2000). Quality, Uncertainty and Consumer Valuation of Fruits and Vegetables. Australian Agribusiness Review, 8.

Romaniuk, J., \& Sharp, B. (2002). Measuring Brand Perceptions: Testing Quantity and Quality. Journal of Targeting, measurement and Analysis for Marketing, 3(11), 218-229.

Sherman, C. (2009). Florida Trend. St. Petersburg, 52(8), 12.

Shewbridge, S. (1998). Probability of Exceeding a Wine Spectator Score: An Evaluation of the Difficulties Wine Consumers Face and Some Coming Changes Wineries Should Prepare For.

Stafford, J., \& Enis, B. (1969). The price-quality relationship: An extension. Journal of Marketing Research, 6(4), 456-459. http://dx.doi.org/10.2307/3150082

Thompson, G. M. et al. (2008). An analysis of Bordeaux Wine Rating, 1975-2005: Implications for the Existing Classification of the Medoc and Graves. Ithaca: The Center for Hospitality Research at Cornell University.

Wehring, O. (2011). CHINA: China set to break into wine big league - research. Just - Drinks Global News, Bromsgrove.

Zeithaml, V. (1988). Consumer Perceptions of Price, Quality and Value: A Means-End Model and Synthesis of Evidence. Journal of Marketing, 52(July), 2-22. http://dx.doi.org/10.2307/1251446

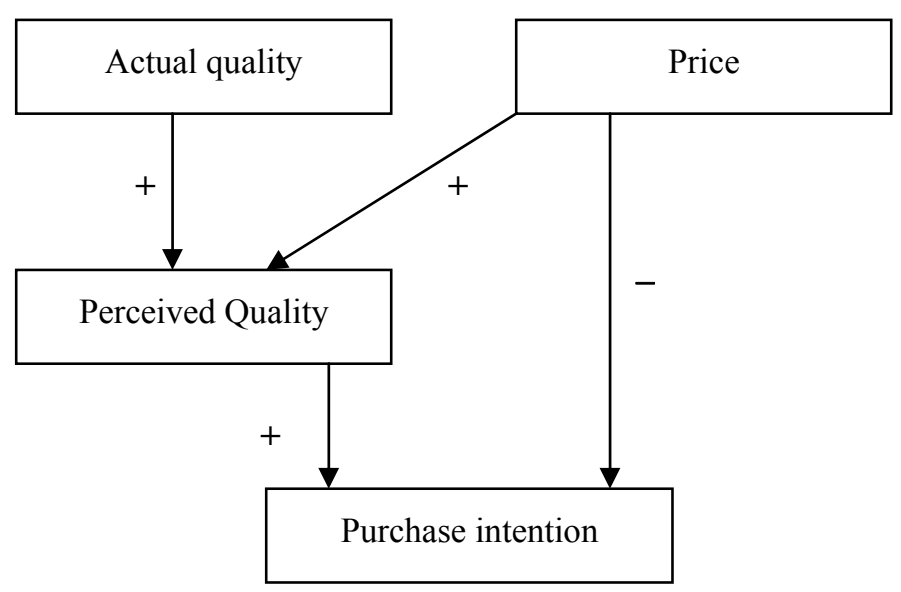

Figure 1. A framework of price-perceived quality heuristic and purchase intention 